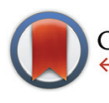

CrossMark \&lick for updates

Cite this: Dalton Trans., 2016, 45 11560

Received 17th May 2016,

Accepted 21st June 2016

DOI: $10.1039 / c 6 d t 01964 a$

www.rsc.org/dalton

\title{
The unexpected case of reactions of halogens and interhalogens with halide substituted $\mathrm{Pd}(\mathrm{II})$ $\sigma$-butadienyl complexes $\dagger$
}

\author{
Thomas Scattolin, ${ }^{a}$ Fabiano Visentin, ${ }^{a}$ Claudio Santo, ${ }^{a}$ Valerio Bertolasi ${ }^{\mathrm{b}}$ and \\ Luciano Canovese*a
}

\begin{abstract}
We have experimentally studied and theoretically interpreted the addition under stoichiometric conditions of halogens or interhalogens to $\sigma$-butadienyl palladium complexes bearing the heteroditopic thioquinolines as spectator ligands. The observed reactions do not involve the expected extrusion of the butadienyl fragment but rather the unpredictable substitution of the halide coordinated to palladium and in some cases also of that bound to the terminal butadienyl carbon. We have explained this peculiar reactivity with a mechanistic hypothesis based on a sequence of selective processes of oxidative addition and reductive elimination involving Pd(Iv) intermediates.
\end{abstract}

\section{Introduction}

Irrespective of the involved mechanism, the formation of aryl or alkyl Pd(II) species is comparatively easier and faster when aryl- or alkyl-iodide, instead of bromide and chloride derivatives are reacted with $\operatorname{Pd}(0)$ substrates. ${ }^{1}$

The product of the oxidative addition, i.e. complexes of the type $\mathrm{L}_{2} \mathrm{PdIR}$ are particularly stable and the substitution of $\mathrm{I}^{-}$ with $\mathrm{Cl}^{-}$or $\mathrm{Br}^{-}$can be obtained by de-halogenation of the iodo-species followed by addition of an appropriate soluble halide ${ }^{2}$ which in the case of reactions carried out in nonprotic solvents can be an expensive compound.

The dehalogenation itself is a delicate process which usually takes a long time and can revert into massive decomposition if the temperature and the incident light are not controlled.

In the present paper we demonstrate that $\sigma$-butadienyl palladium complexes bearing thioquinoline or pyridylthioether as spectator ligands undergo substitution of the iodide bound to palladium(II) by bromide or chloride by a one pot reaction between the above complexes and the interhalogens $\mathrm{IBr}$ and ICl, respectively.

Probably the process above described is not of general importance since in the case of palladium complexes bearing

\footnotetext{
${ }^{a}$ Dipartimento di Scienze Molecolari e Nanosistemi, Università Ca' Foscari, Venice, Italy.E-mail: cano@unive.it

${ }^{b}$ Dipartimento di Scienze Chimiche e Farmaceutiche, Università di Ferrara, Ferrara, Italy

$\dagger$ Electronic supplementary information (ESI) available. CCDC 1472780. For ESI and crystallographic data in CIF or other electronic format see DOI: 10.1039/c6dt01964a
}

phosphoquinoline ${ }^{3}$ and bidentate nitrogen ligands, ${ }^{4}$ a different behavior has been noticed. However, we think that any improvement leading to simplification of the halide metathesis could be of interest.

\section{Results and discussion}

We first noticed the particularity of the reaction involving interhalogens in our attempt to extrude the substituted butadienes (1E,3E)-tetramethyl 1-bromo-4-chlorobuta-1,3-diene1,2,3,4-tetracarboxylate (BCBD) or (1E,3E)-tetramethyl 1-bromo-4-iodobuta-1,3-diene-1,2,3,4-tetracarboxylate (BIBD) by reacting complex 1a with a stoichiometric amount of ICl or IBr according to the well known and extensively used halogen addition and a subsequent elimination sequence liberating the organic fragments from the organopalladium complexes., The almost instantaneously violet color assumed by the reaction mixture in both cases and the related NMR investigations indicate that the reaction products were instead molecular iodine and the complexes $\mathbf{1 c}$ and $\mathbf{1 d}$, respectively (Scheme 1).

The $\sigma$-butadienyl complexes $\mathbf{1 c}$ and $\mathbf{1 d}$ are stable and isolable and their structure is inferred from the ${ }^{1} \mathrm{H}$ and ${ }^{13} \mathrm{C}$ NMR spectra (NMR spectra in Fig. S1, ESI $†$ ). In particular, the position of the pyridine proton $\mathrm{H}^{2}$ in the case of complexes $1 \mathrm{c}$ and $\mathbf{1 d}^{6}$ and that of the terminal butadienyl carbon coordinated to the halide in all the formed complexes is particularly diagnostic. ${ }^{5 i j}$ Therefore, the structure of the complexes is immediately determined owing to the low-field resonance of the terminal butadienyl carbon C-I ( $\delta \sim 100 \mathrm{ppm})$, and the resonance of the quinolinic $\mathrm{H}^{2}$ on the same side of the halide coordinated to 


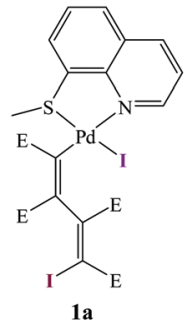

$\mathrm{E}=\mathrm{COOMe}$

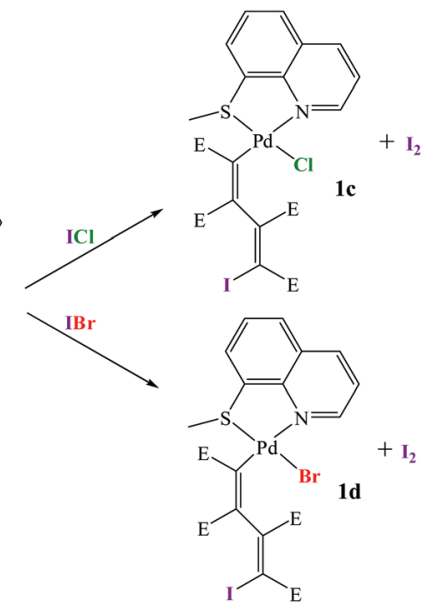

Scheme 1 Studied complexes and products of the reaction between complex $1 \mathrm{a}$ and the interhalogens $\mathrm{ICl}$ or IBr.

palladium, which resonates at $10.24 \mathrm{ppm}$ in the case of the starting complex $2 \mathrm{a}$ and at 9.74 and $9.95 \mathrm{ppm}$, in the case of complexes 1c and 1d.

As discussed in a previously published paper $^{5 j}$ the complexes 1c and 1d can also be obtained by reacting ICl or $\mathrm{IBr}$ with a solution of the palladacyclopentadienyl complex $\left[\operatorname{Pd}(\mathrm{TMQ})\left(\mathrm{C}_{4}(\mathrm{E})_{4}\right)\right](\mathrm{TMQ}=8$-(methylthio)quinoline, $\mathrm{E}=\mathrm{COOMe})$. Furthermore, in the same paper it was shown that the formation of complexes 1c and 1d although less thermodynamically stable was kinetically driven. In fact, the energy of the transition states (TS) leading to the less stable isomer is considerably lower than that which should yield the thermodynamically favored reaction products, i.e. $[\mathrm{Pd}(\mathrm{TMQ}) \mathrm{I}(\mathrm{CE}=\mathrm{CE}-$ $\mathrm{CE}=\mathrm{CECl})]\left(\mathbf{1} \mathbf{c}^{\prime}\right)$ and $[\mathrm{Pd}(\mathrm{TMQ}) \mathrm{I}(\mathrm{CE}=\mathrm{CE}-\mathrm{CE}=\mathrm{CEBr})]\left(\mathbf{1} \mathbf{d}^{\prime}\right) .{ }^{5 j}$

Also in the present case, we resort to a computational study in order to give a correct interpretation to the observed phenomena (Scheme 1). To save computer time, COOMe was substituted with the less disordered CN group (the complexes computationally studied have been consequently indicated by the same labels as the original ones but written in italics). ${ }^{7}$ In the case of the reaction between complex $\mathbf{1 a}$ and $\mathrm{IBr}$ it is apparent from the computational output schematized in Fig. 1 that $\mathrm{I}_{2}$ and complex $\mathbf{1 d}$, among the probable ones represent the favored reaction products from both kinetic and thermodynamic points of view.

The formation and stabilization of the TS might be explained considering that the interhalogen $\mathrm{IBr}$ or $\mathrm{ICl}$ approaches palladium(II) via the more electronegative atom $\mathrm{Br}^{\delta-}$ or $\mathrm{Cl}^{\delta-}$. Thereafter, the hardness of the $\mathrm{Pd}(\mathrm{IV})$ in the intermediate and in TS favors the maintenance of the $\mathrm{Pd}-\mathrm{Br}$ or Pd$\mathrm{Cl}$ bond respectively, eventually collapsing into the experimentally observed compounds $\mathbf{1 d}$ and $\mathrm{I}_{2}$.

According to these observations, we surmise that the interhalogen ICl might also be exploited in the synthesis of complexes bearing chloride and bromide coordinated to palladium and to the terminal butadienyl carbon. Scheme 2 summarizes
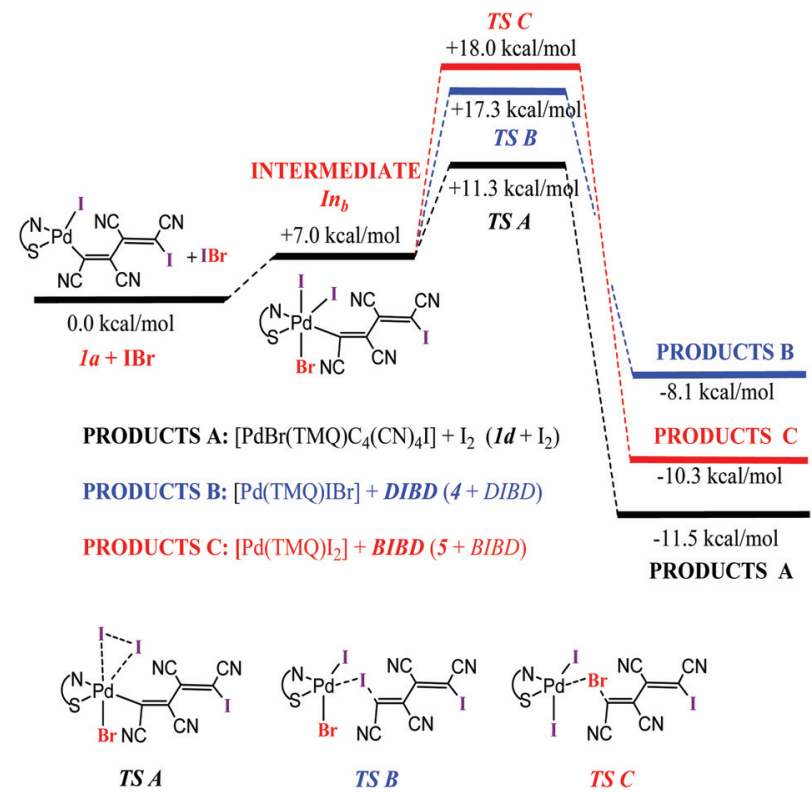

Fig. 1 Computed energies for the reaction between complex $1 \mathrm{a}$ and $\mathrm{IBr}$.

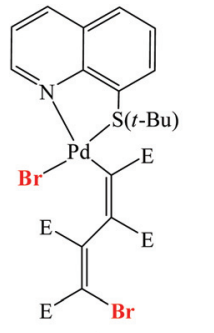

1e
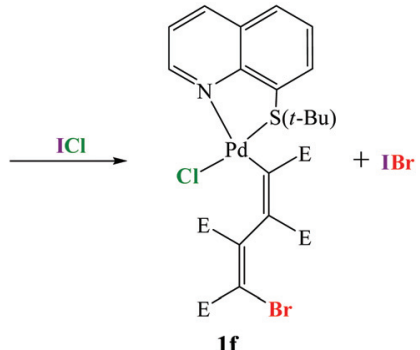

Scheme 2 Synthesis of complex $1 \mathrm{f}$.

the positive aspect of the synthetic approach to complex 1f, as witnessed by the resonance of the pyridine $\mathrm{H}^{2}$ shifting from 9.88 ppm of the starting $1 \mathrm{e}$ derivative ${ }^{5 j}$ to $9.68 \mathrm{ppm}$ of complex 1f. Furthermore, such a result was confirmed by the solid state structure of the isolated complex whose ORTEP $^{8}$ representation is shown in Fig. 2 whereas the description of the structure and the table summarizing the selected bond distances and angles are reported in the crystal structure determination section. Also in this case the computational study is in agreement with the experimental result (Fig. S2, ESI†).

At this point it is worth noting that an alternative synthesis of complex $\mathbf{1 f}$ via the highly unstable $\mathrm{BrCl}$ might be very difficult.

In the light of the above described results, we had the chance to explain the unexpected reactivity observed in the case of the reaction between $\mathbf{1 a}$ and a stoichiometric amount of $\mathrm{Br}_{2}$.

The occurring slow process (ca. $24 \mathrm{~h}$ ), which can be verified from the change of color (from brown to violet) of the solution mixture and confirmed by the NMR spectra, consists in the 


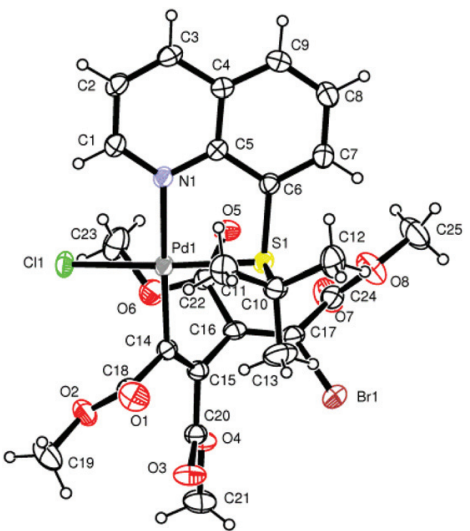

Fig. 2 ORTEP $^{8}$ view of complex 1 showing the thermal ellipsoids at the $30 \%$ probability level.

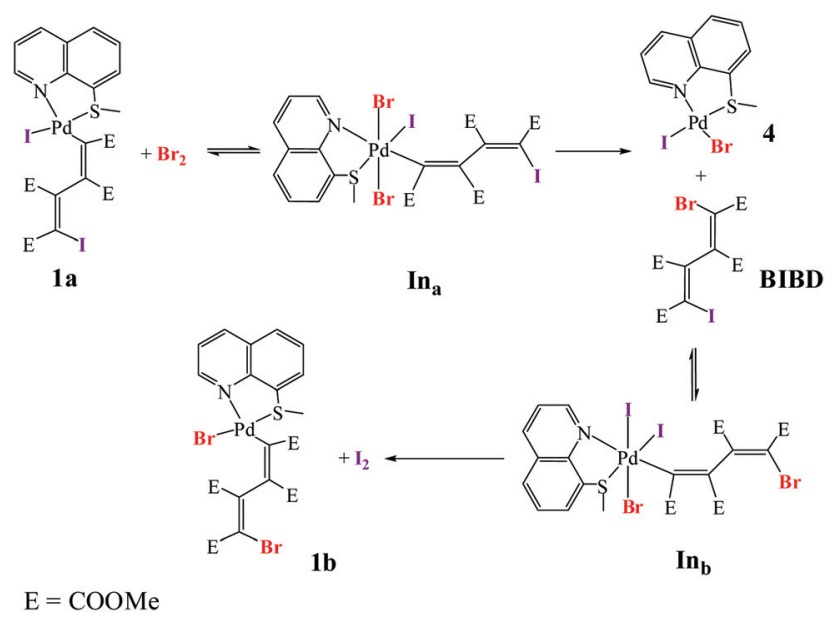

Scheme 3 Proposed mechanism for the reaction $1 \mathrm{a}+\mathrm{Br}_{2} \rightarrow 1 \mathrm{~b}+\mathrm{I}_{2}$.

formation of molecular iodine and complex $\mathbf{1 b}$ where two bromides have substituted both iodides of complex 1a. Notably, no diene displacement is observed in this case either. ${ }^{9}$ In order to maintain the internal consistency we therefore propose for such a reaction a sequence of elementary processes of oxidative addition and reductive elimination, as reported in the following Scheme 3 which is also in agreement with the dedicated computational study shown in Fig. 3.

The involvement of intermediates of the type described in Scheme 3 can also be reasonably cited in the case of the following reactions:

(a) the slow reaction between complex $1 \mathbf{d}$ and a stoichiometric amount of IBr yields the derivative $\mathbf{1 b}$ and $\mathrm{I}_{2}$ and can be interpreted on the basis of the mechanism reported in Scheme 4 involving the same intermediates $\mathbf{I n}_{\mathbf{a}}$ and $\mathbf{I n}_{\mathbf{b}}$.

(b) The ${ }^{1} \mathrm{H}$ NMR spectra immediately detected after the stoichiometric addition of $\mathrm{IBr}$ to $\mathbf{1 d}$ or $\mathrm{Br}_{2}$ to $\mathbf{1 a}$ are identical. This fact can be interpreted on the basis of a fast equilibrium between 1a and 1d species via the common intermediate $\mathbf{I n}_{\mathbf{a}}$ (Scheme 5 and Fig. S3 in the ESI $\dagger$ ).

(c) We have also studied the reaction between complex $\mathbf{1 b}$ and $\mathrm{IBr}$ in excess. The result of this slow process ( $c a .24 \mathrm{~h})$ is summarized in Scheme 6.

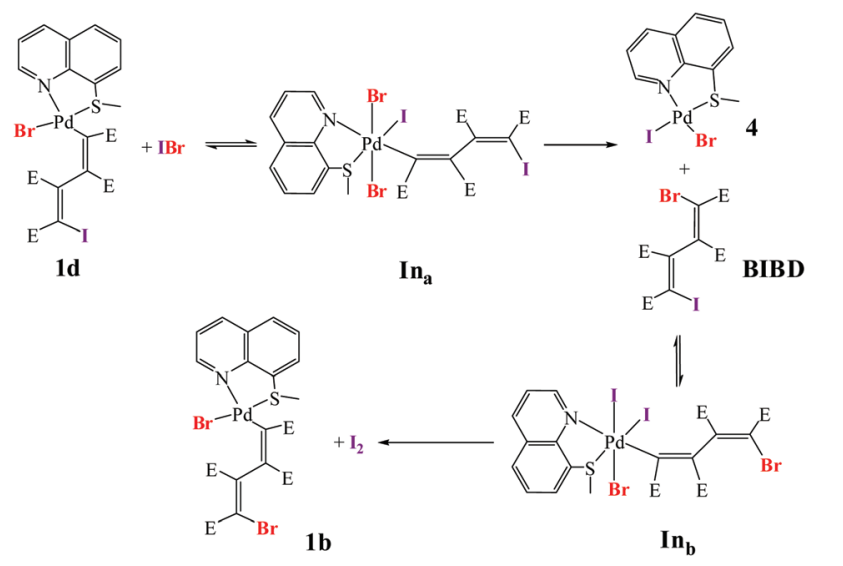

$\mathrm{E}=\mathrm{COOMe}$

Scheme 4 Proposed mechanism for the reaction $1 \mathrm{~d}+\mathrm{IBr} \rightarrow 1 \mathrm{~b}+\mathrm{I}_{2}$.



Fig. 3 Computed energies for the reaction between complex 1a and $\mathrm{Br}_{2}$. 




Scheme 5 Equilibria among $1 \mathrm{a}, \mathrm{Br}_{2}, 1 \mathrm{~d}$ and $\mathrm{IBr}$.


(1)

DBBD<smiles>FC(Br)=C(F)C(F)=C(F)I</smiles>

BIBD

$\mathrm{E}=\mathrm{COOMe}$

Scheme 6 Schematic representation of the reaction: $1 \mathrm{~b}+\mathrm{IBr}_{(\mathrm{exc})} \rightarrow \mathbf{5}+\mathrm{DBBD}+\mathrm{BIBD}+\mathrm{I}_{2}$.

As can be seen the reaction products are the low soluble complex 5 (detected from the ${ }^{1} \mathrm{H}$ NMR spectrum of the inorganic fraction) and a 9:1 mixture of DBBD : BIBD (as shown in the GC-MS spectrum of the organic fraction extracted by diethylether (Fig. S4 in the ESI $\dagger$ )) and $\mathrm{I}_{2}$.

Once again, the mechanism proposed for explaining the composition of the final mixture again takes into account the formation of $\operatorname{Pd}(\mathrm{Iv})$ intermediates as can be seen in Scheme 7.

As a consequence of the attack of the interhalogen $\mathrm{IBr}$ to complex $\mathbf{1 b}$ the formed intermediate $\mathbf{I n}_{\mathbf{c}}$ gives the derivatives $\mathbf{4}$ and 5 (Scheme 7(a)). Obviously, the relative amount of the formed complexes $[5] /[4]$ in the earlier stage of the reaction is close to the $k_{\mathrm{I}} / k_{\mathrm{Br}}$ ratio. However, according to the previously described reaction (see Scheme 3 ) the BIBD diene reacts with complex 4 reforming complex 1b (Scheme 7(b)) which again reacts with $\mathrm{IBr}$ in excess. From the detected final products it is also evident, also supported by the computational study (see Fig. 4), that $k_{\mathrm{I}}>k_{\mathrm{Br}}$ since complex 4 is the limiting reagent which is completely consumed at the end of the reaction.

Finally, we have explored the possibility of using interhalogens for the replacement of the halide coordinated to the palladium centre in substrates different from the $\sigma$-butadienyl complexes. We have therefore reacted the palladium aryl derivatives 2 with $\mathrm{IX}(\mathrm{X}=\mathrm{Br}, \mathrm{Cl})$. In this case the easily and promptly obtained complex 3 confirms the specificity of the reaction which allows the otherwise difficult substitution of a $\mathrm{I}^{-}$coordinated to $\mathrm{Pd}$ with $\mathrm{Br}^{-}$or even with $\mathrm{Cl}^{-}$without preliminary de-halogenation (Scheme 6). However, it is noteworthy that in the case of the reaction of $\mathrm{ICl}$ a side reaction is observed (ca. 10\%). Presumably, the partial displacement of the 1-iodo-4-trifluoromethylbenzene might also take place besides the main reaction yielding the complex $\mathbf{3 b}$ (see Fig. S5, $\mathrm{ESI} \dagger$ ).

It is worth noting that complex 3 a can be directly synthesized by reacting 4-bromo-trifluoromethylbenzene with a $\operatorname{Pd}(0)$ derivative. However, at variance with the smooth and efficient method we propose, the direct synthesis is carried out under drastic conditions and often affected by significant decomposition (Scheme 8).

In conclusion we have experimentally and theoretically proved that addition of halogens or interhalogens to some organometallic palladium compounds induces the substitution of the halide coordinated to the metal and/or that bound to the organic residue instead of the expected extrusion of the organic fragment.

\section{Crystal structure determination of complex $1 \mathrm{f}$}

The geometry around the Pd center is slightly distorted square planar where the four positions are occupied by a halogen atom, $\mathrm{Cl}$, the nitrogen, the sulphur of the (tert-butylsulfanyl) quinoline (TTBQ) ligand, and the carbon $\mathrm{C}_{\alpha}$ of the $1,2,3,4$ tetrakis(methoxycarbonyl)buta-1,3-diene-4-Br-1-yl ligand. The deviation of the Pd1 atom from the average basal plane is 
(a)

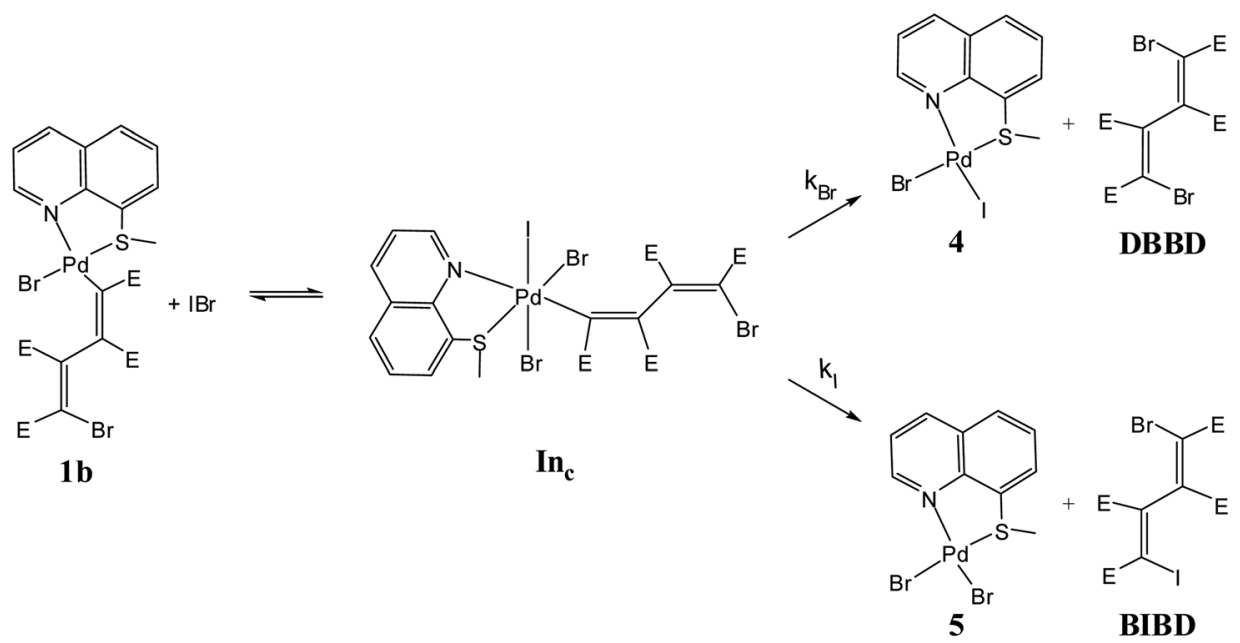

(b)

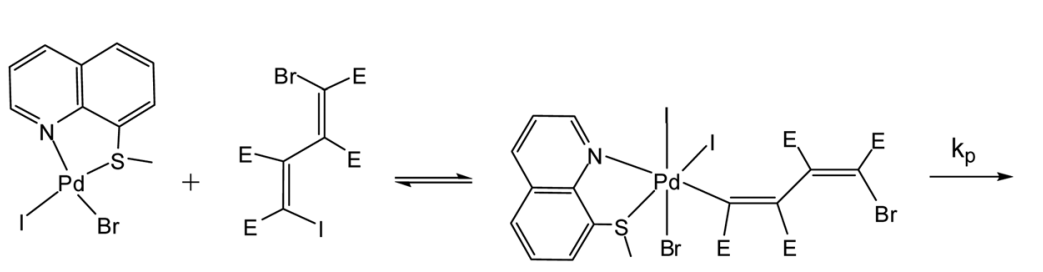

4

BIBD

$\mathbf{I n}_{\mathbf{b}}$<smiles></smiles>

$1 \mathbf{b}$

$\mathrm{E}=\mathrm{COOMe}$

Scheme 7 Proposed mechanism for the reaction $1 \mathrm{~b}+\mathrm{IBr} \rightarrow \mathbf{5}+\mathrm{DBBD}+\mathrm{BIBD}+\mathrm{I}_{2}$.

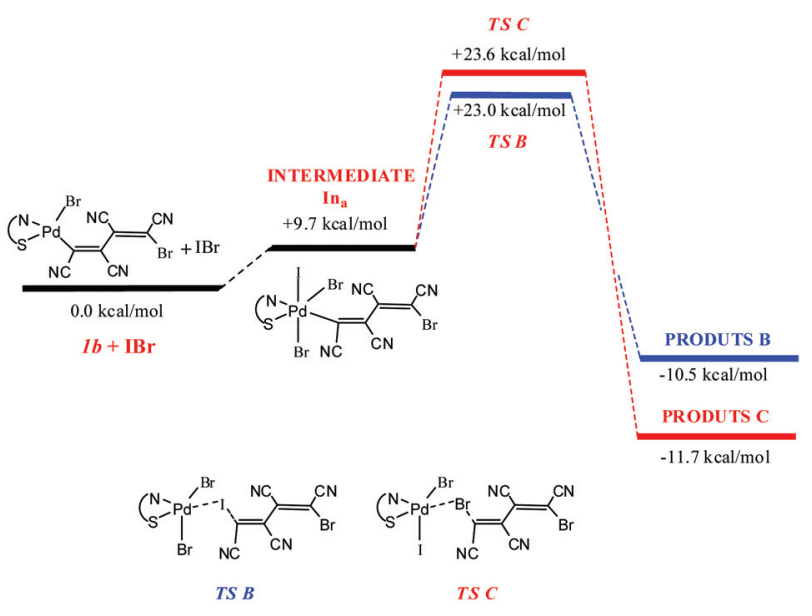

PRODUTS B: $\mathrm{Pd}(\mathrm{TMQ}) \mathrm{Br}_{2}+\boldsymbol{B I B D}(\mathbf{5}+\boldsymbol{B I B D})$

PRODUTS C: Pd(TMQ)IBr + DBBD (4 + DBBD $)$

Fig. 4 Computed energies for the reaction between complex $1 \mathrm{~b}$ and $\mathrm{IBr}$.

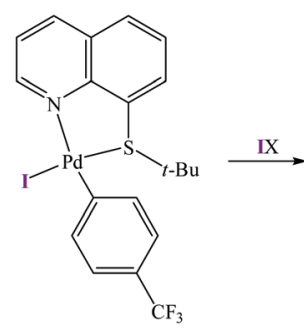

2



$\mathrm{X}=\mathrm{Br} ; \mathbf{3 a}$ $\mathrm{X}=\mathrm{Cl} ; \mathbf{3 b}$

Scheme 8 Products of the reaction between complex 2 and the interhalogens $\mathrm{IBr}$ and $\mathrm{ICl}$.

$0.0872(2) \AA$ A, toward the $\mathrm{C} 10$ carbon. The $\mathrm{C} 14=\mathrm{C} 15-\mathrm{C} 16=\mathrm{C} 17$ buta-1,3-diene moiety adopts the anti-clinal conformation with a torsion angle of $119.1(3)^{\circ}$. The quinoline plane is rotated by $20.25(4)^{\circ}$ with respect to the Pd coordination plane.

The selected bond distances and angles for complex 1f are given in the following Table 1. 
Table 1 Selected bond distances and angles for complex if ( $\AA$ and degrees)

\begin{tabular}{lllr}
\hline Distances & & Angles & \\
\hline Pd1-Cl1 & $2.3244(6)$ & Cl1-Pd1-N1 & $93.56(5)$ \\
Pd1-S1 & $2.2922(6)$ & Cl1-Pd1-S1 & $174.97(3)$ \\
Pd1-N1 & $2.118(2)$ & Cl1-Pd1-C14 & $88.00(7)$ \\
Pd1-C14 & $1.995(3)$ & S1-Pd1-N1 & $84.68(5)$ \\
S1-C6 & $1.774(3)$ & S1-Pd1-C14 & $93.77(7)$ \\
S1-C10 & $1.897(3)$ & N1-Pd1-C14 & $178.44(6)$ \\
C14-C15 & $1.331(4)$ & Pd1-S1-C6 & $97.33(8)$ \\
C15-C16 & $1.491(3)$ & Pd1-S1-C10 & $108.10(9)$ \\
C16-C17 & $1.328(4)$ & Pd1-C14-C15 & $127.1(2)$ \\
C17-Br1 & $1.886(3)$ & Pd1-C14-C18 & $111.6(2)$
\end{tabular}

\section{Conclusions}

The addition of the interhalogens ICl and IBr to the palladium butadienyl complex 1a did not induce the expected extrusion of the butadiene moiety but rather the substitution of the strongly metal bound iodide with the less coordinating chloride or bromide and the displacement of $\mathrm{I}_{2}$. The peculiarity of the observed reactivity drove us to investigate experimentally and theoretically the phenomenon and therefore we have carried out some further reactions and computational studies.

In one case we were able to substitute simultaneously the iodides bound to palladium and terminal butadienyl carbon with two bromides simply by adding bromine to complex $\mathbf{1 a}$.

All the results concur with the formulation of a general mechanism involving selective oxidative addition and reductive elimination via $\mathrm{Pd}(\mathrm{Iv})$ intermediates which eventually gives the final products. In this respect, by reacting complex 1e bearing the two coordinated bromides with ICl we were able to synthesize and resolve the solid state structure of the new complex 1 f bearing one chloride coordinated to palladium and one bromide on the final butadienyl carbon. Moreover, we have shown the versatility of this method by obtaining the complexes $\mathbf{3 a}$ and $\mathbf{3} \mathbf{b}$ through reaction of the aryl palladium species 2 with IBr and ICl, respectively.

\section{Experimental}

\section{Solvents and reagents}

All the distillation processes were carried out under an inert atmosphere (argon). Acetone and $\mathrm{CH}_{2} \mathrm{Cl}_{2}$ were distilled over $4 \AA$ molecular sieves and $\mathrm{CaH}_{2}$, respectively. All other chemicals were commercially available grade products and were used as purchased.

\section{IR, NMR, UV-Vis measurements and elemental analysis}

The IR, ${ }^{1} \mathrm{H},{ }^{13} \mathrm{C}$ and ${ }^{31} \mathrm{P}$ NMR spectra were recorded on a Perkin-Elmer Spectrum One spectrophotometer and on a Bruker 300 Avance spectrometer, respectively.

The ${ }^{1} \mathrm{H}$ NMR reactivity tests were carried out by dissolving the complex under study in $0.8 \mathrm{ml}$ of $\mathrm{CD}_{2} \mathrm{Cl}_{2}$ ([Complex] $\approx$ $1.2 \times 10^{-2} \mathrm{~mol} \mathrm{dm}^{-3}$ ) and adding microaliquots of a concen- trated $\mathrm{CD}_{2} \mathrm{Cl}_{2}$ solution (ca. $1.2 \times 10^{-1} \mathrm{~mol} \mathrm{dm}{ }^{-3}$ ) of $\mathrm{Br}_{2}$, ICl or $\mathrm{IBr}$ and monitoring the signal for the disappearance of the starting complex and the appearance of the final products.

The ligands 8 -(methylthio)quinoline (TMQ), and $8-(t-$ butylthio)quinoline $^{10}$ and complexes $\mathbf{1 a}$ and $1 \mathbf{e}^{5 j}$ were obtained according to published protocols.

The elemental analysis of the synthesized complex was carried out using an Elementar CHN "CUBO micro Vario" analyzer.

\section{Synthesis and characterization of complex if}

To $0.0492 \mathrm{~g}(0.064 \mathrm{mmol})$ of complex 1e (prepared following a published procedure $)^{5 j}$ dissolved in $10 \mathrm{ml}$ of anhydrous $\mathrm{CH}_{2} \mathrm{Cl}_{2}, 0.0114 \mathrm{~g}(0.070 \mathrm{mmol})$ of $\mathrm{ICl}$ dissolved in $5 \mathrm{ml}$ of anhydrous $\mathrm{CH}_{2} \mathrm{Cl}_{2}$ was added under an inert atmosphere (Ar). The resulting mixture was stirred for further $10 \mathrm{~min}$ and then concentrated to a small volume under vacuum. Addition of diethyl ether induces the precipitation of a yellow solid which was filtered off on a Gooch, washed with diethyl ether and $n$-pentane and dried under vacuum at RT. $0.0454 \mathrm{~g}$ (yield 98\%) of the title compound was obtained.

${ }^{1}$ H-NMR (300 MHz, $\left.\mathrm{CDCl}_{3}, \boldsymbol{T}=298 \mathrm{~K}, \mathrm{ppm}\right) \delta: 1.47$ (s, 9H, $\left.\mathrm{C}\left(\mathrm{CH}_{3}\right)_{3}\right), 3.69\left(\mathrm{bs}, 6 \mathrm{H}, \mathrm{OCH}_{3}\right), 3.73\left(\mathrm{~s}, 3 \mathrm{H}, \mathrm{OCH}_{3}\right), 3.89(\mathrm{~s}, 3 \mathrm{H}$, $\left.\mathrm{OCH}_{3}\right), 7.61\left(\mathrm{dd}, 1 \mathrm{H}, J=8.0,4.9 \mathrm{~Hz}, \mathrm{H}^{3}\right), 7.76(\mathrm{~d}, 1 \mathrm{H}, J=$ $7.7 \mathrm{~Hz}, \mathrm{H}^{6}$ ), 8.07 (d, 2H, $\left.J=7.7 \mathrm{~Hz}, \mathrm{H}^{5}, \mathrm{H}^{7}\right), 8.44$ (d, $1 \mathrm{H}, J=$ $\left.8.0 \mathrm{~Hz}, \mathrm{H}^{4}\right), 9.68\left(\mathrm{bd}, 1 \mathrm{H}, \mathrm{H}^{2}\right)$.

${ }^{13} \mathbf{C}\left\{{ }^{1} \mathbf{H}\right\}$-NMR $\left(\mathbf{C D C l}_{3}, \quad \boldsymbol{T}=298 \mathbf{K}, \mathbf{p p m}\right) \delta: 30.2\left(\mathrm{CH}_{3}\right.$, $\left.\mathrm{SC}\left(\mathrm{CH}_{3}\right)_{3}\right), 51.9\left(\mathrm{CH}_{3}, \mathrm{OCH}_{3}\right), 52.2\left(\mathrm{CH}_{3}, \mathrm{OCH}_{3}\right), 53.2\left(\mathrm{CH}_{3}\right.$, $\left.\mathrm{OCH}_{3}\right), 53.2\left(\mathrm{CH}_{3}, \mathrm{OCH}_{3}\right), 59.2\left(\mathrm{C}, \mathrm{C}\left(\mathrm{CH}_{3}\right)_{3}\right), 123.0\left(\mathrm{CH}, \mathrm{C}^{3}\right)$, $124.9(\mathrm{C}, \mathrm{C}=\mathrm{CBr}), 127.4\left(\mathrm{CH}, \mathrm{C}^{6}\right), 129.4\left(\mathrm{C}, \mathrm{C}^{8}\right), 129.9\left(\mathrm{C}, \mathrm{C}^{10}\right)$, $131.1(\mathrm{C}, \mathrm{C}=\mathrm{C}), 131.3\left(\mathrm{CH}, \mathrm{C}^{5}\right), 133.0(\mathrm{C}, \mathrm{C}=\mathrm{C}), 137.6(\mathrm{CH}$, $\left.\mathrm{C}^{7}\right), 139.3\left(\mathrm{CH}, \mathrm{C}^{4}\right), 148.8\left(\mathrm{C}, \mathrm{C}^{9}\right), 153.2\left(\mathrm{CH}, \mathrm{C}^{2}\right), 156.8$ $(\mathrm{C}, \mathrm{C}=\mathrm{C}), 161.4(\mathrm{C}, \mathrm{C}=\mathrm{O}), 164.5(\mathrm{C}, \mathrm{C}=\mathrm{O}), 166.5(\mathrm{C}, \mathrm{C}=\mathrm{O})$, $172.2(\mathrm{C}, \mathrm{C}=\mathrm{O})$. IR (KBr pellets): $\nu_{\mathrm{CO}}=1703,1717,1736 \mathrm{~cm}^{-1}$.

\section{Characterization of complex 5}

Complex 8-(methylthio)quinoline palladium dibromide (5) was separated as an insoluble product in the reaction between complex $\mathbf{1 b}$ and IBr in excess ${ }^{5 j}$ and characterized by elemental analysis and ${ }^{1} \mathrm{H}$ NMR.

Anal. Calcd for $\mathrm{C}_{10} \mathrm{H}_{9} \mathrm{NSBr}_{2} \mathrm{Pd}$ : C, 27.21; H, 2.06; N, 3.17. Found C, 27.73; H 2.13; N, 3.09\% (Elementar C H N "Cubo Micro Vario" Analyzer).

${ }^{1}$ H-NMR (300 MHz, $\left.\mathbf{C D C l}_{3}, \boldsymbol{T}=298 \mathrm{~K}, \mathbf{p p m}\right) \delta: 3.15$ (s, 3H, $\left.\mathrm{SCH}_{3}\right)$ ), $7.71\left(\mathrm{dd}, 1 \mathrm{H}, J=8.2,5.3 \mathrm{~Hz}, \mathrm{H}^{3}\right), 7.84(\mathrm{dd}, 1 \mathrm{H}, J=8.1$, $\left.7.2 \mathrm{~Hz}, \mathrm{H}^{6}\right), 8.09$ (d, $2 \mathrm{H}, J=8.1 \mathrm{~Hz}, \mathrm{H}^{7}$ ), 8.15 (d, $1 \mathrm{H}, J=7.2 \mathrm{~Hz}$, $\left.\mathrm{H}^{5}\right), 8.52\left(\mathrm{~d}, 1 \mathrm{H}, J=8.2 \mathrm{~Hz}, \mathrm{H}^{4}\right), 10.26\left(\mathrm{~d}, 1 \mathrm{H}, J=5.3 \mathrm{~Hz}, \mathrm{H}^{2}\right)$ (Bruker 300 advance spectrometer).

\section{Computational details}

In order to save computer time we have replaced the carboxymethyl group COOMe by the less disordered $\mathrm{CN}$ fragment in the complexes under study. In the following discussion the $\mathrm{CN}$ derivatives will maintain the same labels as the original complexes, albeit in italics (4a and $5 \mathbf{a}$ become $\mathbf{4 a}$ and $\mathbf{5 a}$, respectively). 
We have undertaken a detailed computational study in order to verify the consistency, if any, between the calculated results and our experimental observations in the case of complexes $\mathbf{4 a} / \mathbf{4} \boldsymbol{a}^{\prime}$ and $\mathbf{5} \boldsymbol{a} / \mathbf{5} \boldsymbol{a}^{\prime}$.

Remarkably, our experimental results were not in contrast with the computational study carried out by the Gaussian 09 program, ${ }^{7}$ and despite the implicit limitations $\left(\Delta \Delta G^{\circ} \approx \pm\right.$


have obtained confirmation and hence a possible explanation of the observed trend.

The geometrical optimization of the complexes was carried out without symmetry constraints, using the hyper-GGA functional MO6, ${ }^{11,12}$ in combination with polarized triple- $\zeta$-quality basis sets $(\operatorname{LAN} 2 \mathrm{TZ}(\mathrm{f}))^{13,14}$ and relativistic pseudopotential for the Pd atoms, a polarized double- $\zeta$-quality basis sets (LANL2DZdp) ${ }^{15}$ with diffuse functions for the halogen atoms and polarized double- $\zeta$-quality basis sets $(6-31 G(d, p))$ for the other elements. Solvent effects (acetonitrile, $\varepsilon=37.5$ ) were included using CPCM. ${ }^{16,17}$

The "restricted" formalism was applied in all the calculations. The zero-point vibrational energies and thermodynamic parameters were obtained ${ }^{18}$ by means of the stationary points characterized by IR simulation.

All the computational work was carried out on Intel based $\times 86-64$ workstations.

\section{Crystal structure determination}

The crystal data of complex $\mathbf{1 f}$ were collected at room temperature using a Nonius Kappa CCD diffractometer with graphite monochromated Mo-K $\alpha$ radiation. The data sets were integrated with the Denzo-SMN package ${ }^{19}$ and corrected for Lorentz, polarization and absorption effects (SORTAV). ${ }^{20}$ The structure was solved by direct methods using the SIR97 ${ }^{21}$ system of programs and refined using full-matrix least-squares with all non-hydrogen atoms anisotropically and hydrogens included on calculated positions, riding on their carrier atoms. In this complex an illdefined region of residual electron density in the region around the inversion centre at $0.5,0$, 0.5 was found, probably containing a disordered molecule of diethyl ether. For this reason the program SQUEEZE was used to cancel out the effects of the disordered solvent. SQUEEZE is part of the PLATON program system which attempts to remove mathematically the effects of disordered solvent. ${ }^{22}$

All calculations were performed using PLATON, ${ }^{22}$ SHELXL- $97^{23}$ and PARST ${ }^{24}$ implemented in the WINGX ${ }^{25}$ system of programs. The crystal data are given in Table S1. $\dagger$

Crystallographic data have been deposited at the Cambridge Crystallographic Data Centre and allocated the deposition numbers CCDC 1472780.

\section{Notes and references}

1 (a) J. F. Hartwig, in Organotransition Metal Chemistry, University ScienceBook, 2010, ch. 7; (b) R. H. Crabtree, in
The Organometallic Chemistry of the Transition Metals, Wiley Interscience, 4 th edn, 2005, ch. 6.

2 M. L. Tobe and J. Burgess, in Inorganic Reaction Mechanisms, 1991, ch. 3, Addison Wesley, New York and references therein.

3 L. Canovese, F. Visentin, T. Scattolin, C. Santo and V. Bertolasi, Dalton Trans., 2015, 44, 15049-15058.

4 R. Van Belzen, C. J. Elsevier, A. Dedieu, N. Veldman and A. L. Spek, Organometallics, 2003, 22, 722-736.

5 (a) K. Moseley and P. M. Maitlis, J. Chem Soc., Chem. Commun., 1971, 1604-1605; (b) D. M. Roe, C. Calvo, N. Krishnamachari, K. Moseley and P. M. Maitlis, J. Chem. Soc., Chem. Commun., 1973, 436-438; (c) P. K. Wong and J. K. Stille, J. Organomet. Chem., 1974, 70, 121-132; (d) H. Kurosawa, A. Urabe, K. Miki and N. Kasai, Organometallics, 1986, 5, 2002-2008; (e) K. Isobe, K. Nanjo, Y. Nakamura and S. Kawaguchi, Bull. Chem. Soc. Jpn., 1986, 59, 2141-2149; (f) J. Albert, J. Granell and J. Sales, Polyhedron, 1989, 8, 2725-2726; (g) M. Kubata, S. C. Boegeman, R. Keill and C. G. Webb, Organometallics, 1989, 8, 16161620; (h) S. Chattopadhyay, c. Sinha, P. Basu and A. Chacroworty, J. Organomet. Chem., 1991, 414, 421-431; (i) L. Canovese, C. Santo, T. Scattolin, F. Visentin and V. Bertolasi, J. Organomet. Chem., 2016, 808, 48-56; (j) L. Canovese, C. Santo, T. Scattolin, F. Visentin and V. Bertolasi, Polyhedron, 2016, 113, 25-34; (k) K. Muñiz, Angew. Chem., Int. Ed., 2009, 48, 2-14.

6 (a) L. Canovese, F. Visentin, G. Chessa, P. Uguagliati and G. Bandoli, Organometallics, 2000, 19, 1461-1463; (b) L. Canovese, F. Visentin, G. Chessa, P. Uguagliati, C. Santo and A. Dolmella, Organometallics, 2005, 24, 325730308.

7 M. J. Frisch, G. W. Trucks, H. B. Schlegel, G. E. Scuseria, M. A. Robb, J. R. Cheeseman, G. Scalmani, V. Barone, B. Mennucci, G. A. Petersson, H. Nakatsuji, M. Caricato, X. Li, H. P. Hratchian, A. F. Izmaylov, J. Bloino, G. Zheng, J. L. Sonnenberg, M. Hada, M. Ehara, K. Toyota, R. Fukuda, J. Hasegawa, M. Ishida, T. Nakajima, Y. Honda, O. Kitao, H. Nakai, T. Vreven, J. A. Montgomery Jr., J. E. Peralta, F. Ogliaro, M. Bearpark, J. J. Heyd, E. Brothers, K. N. Kudin, V. N. Staroverov, R. Kobayashi, J. Normand, K. Raghavachari, A. Rendell, J. C. Burant, S. S. Iyengar, J. Tomasi, M. Cossi, N. Rega, J. M. Millam, M. Klene, J. E. Knox, J. B. Cross, V. Bakken, C. Adamo, J. Jaramillo, R. Gomperts, R. E. Stratmann, O. Yazyev, A. J. Austin, R. Cammi, C. Pomelli, J. W. Ochterski, R. L. Martin, K. Morokuma, V. G. Zakrzewski, G. A. Voth, P. Salvador, J. J. Dannenberg, S. Dapprich, A. D. Daniels, O. Farkas, J. B. Foresman, J. V. Ortiz, J. Cioslowski and D. J. Fox, Gaussian 09', 2009, Gaussian, Inc., Wallingford, CT.

8 M. N. Burnett and C. K. Johnson, ORTEP III, Report ORNL-6895, 1996, Oak Ridge National Laboratory, Oak Ridge, TN.

9 As observed elsewhere, only does the addition of $\mathrm{Br}_{2}$ in stoichiometric excess allow the extrusion of the diene from complex $\mathbf{1 b}$ (see ref. $5 i$ and $j$ ). Thus, adding an excess of 
$\mathrm{Br}_{2}$ to a solution of $1 \mathrm{a}$ eventually yields DBDB, $\mathrm{I}_{2}$ and $\left[\mathrm{Pd}(\mathrm{TMQ}) \mathrm{Br}_{2}\right](5)$ as the reaction products.

10 L. Canovese, F. Visentin, C. Biz, T. Scattolin, C. Santo and V. Bertolasi, J. Organomet. Chem., 2015, 786, 21-30.

11 Y. Zhao and D. G. Truhlar, Acc. Chem. Res., 2008, 41, 157167.

12 Y. Zhao and D. G. Truhlar, Theor. Chem. Acc., 2008, 120, 215-241.

13 P. J. Hay and W. R. Wadt, J. Chem. Phys., 1985, 82, 270-283, 299-310.

14 L. E. Roy, P. J. Hay and R. L. Martin, J. Chem. Theory Comput., 2008, 4, 1029-1031.

15 C. E. Check, T. O. Faust, J. M. Bailey, B. J. Wright, T. M. Gilbert and L. S. Sunderlin, J. Phys. Chem. A, 2001, 105, 8111-8116.

16 V. Barone, M. Cossi and J. Tomasi, J. Chem. Phys., 1997, 107, 3210-3221.

17 V. Barone and M. Cossi, J. Phys. Chem. A, 1998, 102, 19952001.
18 (a) C. J. Cramer, Essentials of Computational Chemistry, Wiley, Chichester, 2nd edn, 2004; (b) F. Jensen, Introduction to Computational Chemistry, Wiley, Chichester, 2nd edn, 2007.

19 Z. Otwinowski and W. Minor, in Methods Enzymology, ed. C. W. Carter and R. M. Sweet, Academic Press, London, 1997, vol. 276, Part A, pp. 307-326.

20 R. H. Blessing, Acta Crystallogr., Sect. A: Fundam. Crystallogr., 1995, 51, 33-38.

21 A. Altomare, M. C. Burla, M. Camalli, G. L. Cascarano, C. Giacovazzo, A. Guagliardi, A. G. Moliterni, G. Polidori and R. Spagna, J. Appl. Crystallogr., 1999, 32, 115119.

22 A. L. Spek, Acta Crystallogr., Sect. D: Biol. Crystallogr., 2009, 65, 148-155.

23 G. M. Sheldrick, SHELX-97, Program for Crystal Structure Refinement, University of Gottingen, Germany, 1997.

24 M. Nardelli, J. Appl. Crystallogr., 1995, 28, 659-659.

25 L. J. Farrugia, J. Appl. Crystallogr., 1999, 32, 837-838. 